\title{
ASYMMETRIC ADJUSTMENTS OF PRICE AND OUTPUT
}

\author{
P.A. Tinsley and Reva Krieger * \\ version: June 1997
}

\begin{abstract}
Asymmetries in price adjustment can reconcile contrasts between rapid price movements in inflationary episodes, consistent with classical theories of flexible pricing, and sluggish price responses in contractions, consistent with Keynesian theories of sticky price adjustments. Nonparametric analysis of SIC two-digit industry data indicates that negative asymmetries are more pronounced for real outputs than for nominal outputs, suggesting reversed positive asymmetries in producer pricing. Pricing decision rules are estimated to distinguish between asymmetries in conditioning shocks and asymmetries in producer responses. Two rational motives for asymmetric pricing are supported.
\end{abstract}

Keywords: Asymmetric trend deviations, rational error correction, producer pricing.

*Authors' addresses are: Federal Reserve Board, Washington, D.C. 20551, ptinsley@frb.gov; and International Monetary Fund, Washington, D.C. 20431, rkrieger@imf.org. Views presented are those of the authors and do not necessarily represent those of the Federal Reserve Board or the International Monetary Fund. Our thanks to R. Sweeney and two referees for useful suggestions. Forthcoming in Economic Inquiry. 


\section{INTRODUCTION}

A sharp difference persists in economics regarding the dynamic adjustments of prices. In classical theories, markets are continuously cleared by flexible prices with instantaneous adjustments of prices to agents' perceptions of monetary policy. In contrast, Keynesian theories suggest non-auction prices are slow to adjust to equilibrium with short-run clearing achieved by adjustments of transacted quantities. A sufficient reason for the continued split in descriptions is that both views are supported by empirical evidence. The case for sticky prices is not easily squared with the rapid movements of prices in inflationary episodes, as reviewed by Sargent [1982]. On the other hand, the assumption of instantaneously flexible producer prices seems inconsistent with the lengthy spells of rigid prices documented in Carlton [1986] and Blinder [1991] and the sluggish price responses estimated by Sims [1992] and Christiano, Eichenbaum, and Evans [1994].

A third alternative is that both classical and Keynesian characterizations may be describing price behavior in different stages of business cycles if producers respond asymmetrically to positive and negative deviations from trends. Prompt producer corrections of prices that are below trends can account for the essential classical feature of flexible price responses to expected inflation. Conversely, resistance to margin reductions for prices that are above trends can support the Keynesian description of sluggish adjustment that leaves prices at excessively high levels over extended intervals. ${ }^{1}$

This paper examines the case for asymmetric pricing in four steps:

- A recent literature, vid. Sichel [1993], indicates that manufacturing output exhibits various negative asymmetries, such as larger trend deviations (in absolute value) at cyclical troughs than at peaks. In section II, a search for similar asymmetries in the outputs of SIC two-digit industries finds that negative asymmetries in trend deviations are more pronounced in real outputs than in nominal outputs. This suggests an offsetting positive asymmetry in industry prices where below-trend prices are more readily raised than above-trend prices are lowered.

- Although suggestive, reported measures of asymmetric data features are atheoretic so sources of asymmetric behavior are ambiguous. To help distinguish between the roles of exogenous shocks and endogenous responses in producer pricing, benchmark structural models of symmetric pricing are examined in section III. The standard frictions model of gradual price corrections based on costly adjustment of price levels, such as Rotemberg [1982; 1987], is rejected for prices of manufacturing industries. Empirical models of industry pricing appear to be consistent with an extended definition of frictions where producers aim to smooth moving averages of prices and inflation rates.

\footnotetext{
${ }^{1}$ Although short-run inflexibility of nominal prices is a tenet of new-Keynesian theories of business cycle contractions, an awkward implication of symmetrically sticky price models is that prices may get stuck also at levels that are too low for market clearing.
} 
- The extended frictions model of symmetric pricing is then used in section IV to identify sources of asymmetries in producer pricing. Empirical tests indicate that the effects of trend deviations in output on price adjustments are either statistically insignificant or inconsistent with positive asymmetries in pricing, and that asymmetric pricing appears to be a structural decision that depends on whether the industry price is below or above its trend.

- Section V reviews several interpretations of asymmetric pricing and suggests a representative indicator for each theory. Industry values of these indicators are compared with industry estimates of asymmetric pricing; the cross-industry correlations support two rational motives for positive asymmetries in producer pricing. Section VI concludes.

\section{ASYMMETRIES IN INDUSTRY OUTPUT}

This section presents nonparametric measures of asymmetric behavior in output. In contrast to previous work on macroeconomic aggregates, discussion is aimed at outputs of SIC two-digit industries in manufacturing. A comparison between real and nominal outputs is also introduced which suggests an asymmetry in industry pricing.

Descriptions of asymmetric behavior were prominent in prewar business cycle literature, such as Mitchell [1927], Means [1935], and Haberler [1938]. The issue of cyclical asymmetries then fell into disfavor with the postwar emergence of models of agent behavior based on stochastic linear difference equations. However, over the last decade, several studies have resuscitated atheoretic measurement of cycle asymmetries, with mixed findings for asymmetry. Neftci [1984] presents evidence of asymmetry in the aggregate rate of unemployment, with unemployment faster to rise and slower to fall. Falk [1986] and DeLong and Summers [1986] confirm the positive asymmetry in the unemployment rate but find no evidence of matching asymmetries in the movements of detrended GNP. By contrast, Goodwin and Sweeney [1993] provide evidence of negative asymmetry in real GNP growth where positive growth rates are constrained by a real output ceiling, as suggested by Friedman [1993]. Because the amplitudes of cyclical fluctuations are larger in goods than in services, recent analyses of McNevin and Neftci [1991], McQueen and Thorley [1993], and Sichel [1993] examine cyclical movements in industrial production and indicate that the behavior of goods output appears to be different in recessions than in expansions.

The patterns of asymmetric movements reported for aggregate output vary by study, in part due to different definitions of asymmetry. The premise advanced by Mitchell [1927] is that output falls faster from cyclical peak to trough than in the expansion from trough to peak. Termed "steepness" asymmetry by Sichel [1993], a pattern of slow ascents and rapid descents will be described here as negative growth rate asymmetry. Asymmetries in positive and negative growth rates of detrended output are supported for production of durable goods in McNevin and Neftci [1991] but rejected for total industrial production by Sichel [1993]. 
A contrasting pattern of cyclical asymmetry was suggested by the nonlinear business cycle model of Hicks [1950] where output expansions are eventually constrained by capacity ceilings due to shortages of labor or fixed capital. Because capacity ceilings place upper bounds on output growth in expansions that are not matched by comparable lower bounds on output contractions in recessions, the average squared negative deviation from trend may exceed the average squared positive deviation from trend. ${ }^{2}$ Sichel [1993] indicates that trend deviations at troughs are larger (in absolute value) than trend deviations at peaks for industrial production, depending on the method of detrending. Dubbed "deepness" asymmetry by Sichel, this pattern is described here as negative gap asymmetry, to emphasize that this is a pattern of trend deviations in log levels rather than in $\log$ differences.

The analysis of industry outputs that follows is directed at three unresolved issues:

- First, are asymmetries reported for aggregate goods output also reproduced in industry disaggregations? If asymmetric motion is only apparent in total goods output then it is unlikely to be an intrinsic characteristic of producer behavior but a result of aggregation, perhaps due to cyclical shifts in the composition of aggregate demand.

- Second, are either of the asymmetric patterns catalogued by Sichel [1993] pervasive in industry behavior? As indicated later, if displacements away from a trend are due largely to unanticipated shocks then asymmetry in gaps on different sides of the trend, due to different producer responses to positive and negative shocks, is amenable to structural interpretations. By contrast, asymmetry in detrended growth rates is more difficult to rationalize in a typical shock/response model of behavior because the set of positive (negative) growth rates encompasses both the return from a trough (peak) turning point to the trend and the subsequent departure from the trend to the next peak (trough).

- Third, if systematic asymmetries are detected in industry outputs, are they also reproduced in nominal output? If the same asymmetries in real output are reproduced in nominal output then an intrinsic asymmetry in producer pricing, such as the "administered pricing" conjecture of Means [1935], is unlikely to be an important cause of cyclical asymmetries in output.

\section{Selecting the Trends of Industry Outputs and Prices.}

Although the empirical literature cited above presents evidence of asymmetries in economic time series, there does not appear to be a consensus among economists that asymmetric responses are a fundamental characteristic of agent behavior. In the case of trending variables, a sufficient reason for scepticism is that empirical evidence of asymmetries appears to depend on the method

\footnotetext{
${ }^{2}$ Asymmetry in squared deviations is not inconsistent with standard detrending constructions that yield equal sums (in absolute value) of negative and positive trend deviations.
} 
of detrending, vid. Canova [1993]. If the true trend is overstated then the average of negative deviations from trend will tend to exceed the average of positive deviations, biasing results towards a finding of negative asymmetry, and vice versa for underestimates of the trend. The analytical focus of the literature on asymmetric trend deviations is further blurred by the wide assortment of available detrending methods. ${ }^{3}$

In the case of manufacturing industries, postwar time series on industry outputs and prices are consistent with difference-stationary behavior so it appears appropriate to select I(1) trends that are cointegrated with the relevant industry prices and outputs. For log industry output, $q_{t}$, the trend measures used here are based on FRB staff estimates of capacity utilization, Raddock [1985]. The industry log utilization rates are stationary, so the sample mean of an industry utilization rate may be interpreted as the long-run preferred utilization rate of producers. Trend output or the $\log$ of preferred output, $q_{t}^{*}$, is constructed by subtracting the log of the industry utilization rate from $\log$ output, $q_{t}^{*} \equiv q_{t}-u_{t}$. The log of the preferred utilization rate is normalized to zero by removing the sample mean to ensure that the sum of sample trend deviations is zero, $\sum_{t} u_{t}=0$.

The log of industry nominal output, $n_{t}$, is the sum of log output plus log price, $n_{t}=q_{t}+p_{t}$. Under imperfect competition by identical producers, the optimal industry price can be expressed as a markup over marginal cost. ${ }^{4}$ Under the assumption that gross production is Cobb-Douglas, the log price trend, $p^{*}$, of each industry is constructed by cointegration regressions on weighted indexes of the log prices of raw and intermediate materials inputs and unit labor costs, where the index weights reflect the input requirements of the relevant industry. As one would hope for exogenous trend constructions, vid. Gonzalo and Granger [1995], systematic reductions in the trend deviations of both industry price and output are dominated by the error correction responses of industry price, $\Delta p_{t}$, and output, $\Delta q_{t}$, whereas error correction responses of trend price, $\Delta p_{t}^{*}$, and trend output, $\Delta q_{t}^{*}$, are negligible. ${ }^{5}$

\section{Contrasts of real and nominal output trend deviations.}

Asymmetries in trend deviations by industry real and nominal output are displayed in table I. The basic measure of asymmetry in table $I$ is the ratio of the positive semi-variance (the mean of squared positive deviations from trend) to the negative semi-variance (the mean of squared negative

\footnotetext{
${ }^{3}$ Cautions against indiscriminate use of detrending methods include those of Nelson and Kang [1981] on deterministic trends, Osborn [1993] on detrending by moving average filters, and Harvey and Jaeger [1993] on detrending by the Hodrick-Prescott filter.

${ }^{4}$ In standard formulations, such as Waterson [1984], the $\log$ margin is $\log \left[1-(s \eta)^{-1}\right]^{-1}$ where $\eta$ denotes the price elasticity of industry demand and $s$ is the number of producers, illustrating monoply or competitive solutions as $s \rightarrow 1$ or $s \rightarrow \infty$

${ }^{5} \mathrm{An}$ appendix on the integration orders, cointegrating trends, and error correction responses of industry prices and outputs is available from the authors.
} 
deviations from trend). The entries in table I will be one if the distribution of trend deviations is symmetrical but less than one if the distribution is negatively skewed. ${ }^{6}$

Negative asymmetry in growth rates is rejected for detrended real GNP by DeLong and Summers [1986] and Sichel [1993]. The first two columns of table I indicate the extent of asymmetry in the growth rates of detrended industry outputs, $\Delta q_{t}-\Delta q_{t}^{*}$. Trend output, $q_{t}^{*}$, is measured in the first column by a simple linear trend, labeled OLS trend, and in the second column by the cointegrating construction based on FRB capacity utilization rates, labeled I(1) trend. Negative asymmetry in growth rates appears to be reasonably widespread among manufacturing industries, and the degree of asymmetry is relatively insensitive to the choice of trend. The ratio of positive to negative semi-variances for the growth rates of real output is less than unity at a $90 \%$ significance level or better for seven industries and considerably less than unity for all but three or four industries.

The third column in table I displays the ratio of semi-variances in the growth rates of trend deviations in industry nominal outputs. Here, there appears to be much less evidence of negative asymmetry in growth rates. The semi-variance ratios for nominal output are generally larger than those for real output and about a third of the ratios are greater than one, indicating that the positive growth rates of detrended nominal output are larger than the negative growth rates in those industries.

The right half of table I displays asymmetries in the levels of trend deviations where the relevant measure is the gap deviation, $q_{t}-q_{t}^{*}$. As with the growth rate measures, the first two columns in the right half of table I measure the asymmetry in squared output gaps for two measures of trend in output. In the case of the linear OLS trend, there is no clear tendency towards negative gap asymmetry with about half of the industries above one and the remainder below. However, because OLS regressions minimize the sum of squared deviations, the linear trend is biased against gap asymmetry. Even if negative gap asymmetry exists, the OLS estimator pulls down the estimated trend in order to reduce the squared outlier effects of the larger negative gaps.

A different picture emerges in the next column of table I, labeled I(1) trend, which uses the cointegrating trends based on preferred utilization of capacity output. This measure suggests negative gap asymmetry in output is even more pervasive across industries than the asymmetry of growth rates shown in the first half of the table. The ratio of the semi-variances of positive trend gaps to negative trend gaps is less than one for all but one industry. More striking than the general incidence of negative gap asymmetry is the severity of the average shortfall from trend utilization

\footnotetext{
${ }^{6}$ Let $\epsilon_{t}$ denote a deviation from trend in period $t$. As noted earlier, the mean trend deviation is zero by construction, $\sum_{t} \epsilon_{t}=0$. Asymmetry in "gaps" is measured by the ratio of the mean of squared positive deviations to the mean of squared negative deviations, $\left(\sum_{t}\left[\epsilon_{t}^{+}\right]^{2} / n^{+}\right) /\left(\sum_{t}\left[\epsilon_{t}^{-}\right]^{2} / n^{-}\right)$, where there are $n^{+}$positive trend deviations, $\epsilon_{t}^{+}>0$, and $n^{-}$negative trend deviations, $\epsilon_{t}^{-}<0$. Asymmetry in growth rates is similarly measured by the ratio of the mean of squared positive first-differences in the trend deviations to the mean of squared negative first-differences.
} 
of capacity production that occurs in many industries. In about half of the industries, the average squared negative output gap is more than double the size of the average squared positive output gap.

The last column in table I shows asymmetry gap measures for industry nominal output. The incidence of negative asymmetry is much less evident for nominal output. By contrast with the measure for real output in the preceding column, the measure of gap asymmetry for nominal output moves toward or past unity for most industries, and negative gap asymmetry remains statistically significant for only three industries.

The finding that negative gap asymmetry is more pervasive and marked for real output than for nominal output also suggests a reverse positive asymmetry in pricing. If industry price is symmetrically sluggish about its own trend, we might expect the gap asymmetry in real output to be more-or-less reproduced in nominal output. The fact that negative gap asymmetry in nominal output is generally much closer to unity or even replaced by positive asymmetry suggests that negative asymmetries in real output are often matched by positive asymmetries in prices, yielding more symmetric distributions for nominal output gaps.

Although results in table I indicate sizable asymmetries in the production and pricing of manufacturing producers, it is important to not overinterpret what can be established by atheoretic measurement. Negative gap asymmetry for output may indicate that the average negative shock to output is larger than the average positive shock or that production is slower to recover from adverse shocks. Indeed, in the absence of an articulated model of producer behavior, it is not clear whether motion away from trends represent unforeseen displacements due to shocks or planned overshooting of trends by producers.

To reduce such ambiguities associated with atheoretic analysis, the remainder of the paper explores possible sources of asymmetries using structural models of producer behavior. Specific dynamic optimality conditions will be discussed in some detail later. However, a brief preview of this structural framework is provided by a representative Euler condition for optimal adjustment of a producer decision variable such as output or price

$$
E_{t}\left\{f\left(y_{t-i}, y_{t}, y_{t+i} \mid \theta\right)-y_{t}^{*}\right\}=0
$$

where $f($.$) is a two-sided function of leads and lags in the decision variable, y ; \theta$ denotes the parameters of $f($.$) that are shaped largely by the nature of the frictions or "adjustment costs"$ that confront producers; and the forcing term of the Euler equation, $y_{t}^{*}$, is the effective trend or long-run target of the decision variable. In the absence of adjustment costs, $f(.) \equiv y_{t}$, and the expected gap or trend deviation, $E_{t}\left\{y_{t}-y_{t}^{*}\right\}$, is zero. This simple structural model of producer behavior suggests two sources of asymmetries in realized gaps. One is exogenous and stems from 
potential asymmetries in unpredictable shocks to the forcing term; the other is endogenous due to asymmetric responses by producers, captured by state-conditional movements in the parameters of the Euler equation, $\theta$.

Output, price, or both may be viewed as the effective instrument(s) of producers. The remainder of this paper focuses on friction models of pricing, $y_{t} \equiv p_{t}$. The reason for this is the evidence in table I that many industries exhibit both negative gap asymmetries in output and positive gap asymmetries in pricing. If output movements capture the original source of asymmetry then the negative asymmetry in output should be able to explain the positive asymmetry in pricing. An alternative conjecture is that resistance to downward adjustments of nominal prices, as in Means [1935] and Tobin [1972], may exacerbate contractions of industry production in recessions. This interpretation suggests an endogenous characterization of asymmetric pricing where the parameters of linear pricing rules, $\theta$, exhibit asymmetric responses to positive and negative trend deviations in price. Tests of both interpretations of asymmetric pricing are discussed in a later section.

\section{STRUCTURAL MODELS OF SYMMETRIC PRICE ADJUSTMENTS}

Although the final goal of this paper is to identify asymmetries in pricing, this section first develops a symmetric pricing model to be used as a testbed for asymmetric variations. Without a reasonable benchmark model, estimated asymmetries could plausibly be attributed to features of uninteresting ad hoc fixes, such as autocorrelated errors.

The standard frictions model of gradual price responses, such as Rotemberg [1982; 1987], is based on costly adjustment of price levels. The initial subsection shows that the standard model is not supported by manufacturing prices, where empirical problems include substantial residual autocorrelation and rejection of the overidentifying restrictions associated with rational expectations. The second subsection develops a more general model of frictions in dynamic pricing that appears to be accepted by industry data.

\section{Rational pricing under quadratic costs of adjusting levels.}

By construction, a cointegrating target price path, $p_{t}^{*}$, is an equilibrium objective for the industry price, $p_{t}$, in the absence of stochastic shocks. However, once displaced from the target path, due to errors in estimating costs or demand, various frictions or dynamic market strategies may impede an immediate return to the target path.

A tractable description of gradual price adjustments is provided by Rotemberg [1982; 1987] where a second-order expansion of profits about an equilibrium profit-maximizing price represents producers as minimizing the discounted sum of squared deviations about the equilibrium price path 
and the cost of squared changes in the level of the price.

$$
p_{t}=\operatorname{argmin}\left(E_{t}\left\{\sum_{i=0}^{\infty} B^{i}\left[b_{0}\left(p_{t+i}-p_{t+i}^{*}\right)^{2}+b_{1}\left(p_{t+i}-p_{t+i-1}\right)^{2}\right]\right\}\right) \text {, }
$$

where $E_{t}\{$.$\} denotes producer expectations given information through t-1$, and $B$ is a (quarterly) discount factor. ${ }^{7}$

The associated first-order condition for optimal price adjustment is described by a second-order Euler equation, written here as a function of two first-order polynomials in lag, $L$, and lead $F$, operators where $L x_{t}=x_{t-1}$ and $F x_{t}=x_{t+1}$.

$$
E_{t}\left\{A(B F) A(L) p_{t}-A(1) A(B) p_{t}^{*}\right\}=0
$$

On the left-hand-side of $3, A(L)$ denotes the first-order polynomial in the lag operator, $A(L) \equiv$ $(1-\lambda L)$, and $A(B F)$ is the matching factor polynomial in the lead operator. These polynomials are balanced on the other side of the minus sign by the sums of the polynomial weights, $A(1) \equiv 1-\lambda$ and $A(B) \equiv 1-\lambda B .^{8}$

As is well-known, e.g., Tinsley [1970b], the optimal decision rule under quadratic adjustment costs can be written as a partial adjustment of the decision instrument towards a moving target. Multiplying equation 3 by the inverse of the lead polynomial, $A(B F)^{-1}$, and rearranging gives

$$
\begin{aligned}
\Delta p_{t} & =E_{t}\left\{A(1) A(B) A(B F)^{-1} p_{t}^{*}+\left(\Delta p_{t}-A(L) p_{t}\right)\right\}, \\
& =A(1) A(B) E_{t}\left\{\sum_{i=0}^{\infty}(\lambda B)^{i} p_{t+i}^{*}\right\}-A(1) p_{t-1}, \\
& =A(1)\left[S_{t}\left(\lambda B, p^{*}\right)-p_{t-1}\right]
\end{aligned}
$$

where $S_{t}($.$) denotes the moving target of discounted forward trend prices. { }^{9}$

In the case of I(1) difference-stationary variables, such as the industry prices considered here, the decision rule in equation 4 can be reformulated also as a rational error correction rule, Tinsley [1993]. To show this, we first identify the unobserved expectations, $E_{t}\{$.$\} , by assuming that agents'$

\footnotetext{
${ }^{7} \mathrm{~B}$ is set to .98 , approximating the postwar annual real return to equity of about 8 percent. No empirical results in this paper are overturned by modest variations in $B$.

${ }^{8}$ The characteristic roots of 3 are $\lambda$ and $(\lambda B)^{-1}$, where $\lambda$ is the fractional root of the equation, $(1-\lambda B)\left(\lambda^{-1}-\right.$ 1) $-b_{0} / b_{1}=0$. This solution will always exist for $b_{0} / b_{1}>0$.

${ }^{9}$ As noted by Rotemberg [1987], the optimal price response under quadratic price level friction is equivalent to the staggered price adjustment model of Calvo [1983] where producers are subject to an invariant distribution of random delays in price signals.
} 
forecasts are rational and captured by the VAR model,

$$
z_{t}^{e}=H z_{t-1}
$$

where the $n \times 1$ vector $z_{t-1}$ defines the effective information set of the agents, $H$ is the $n \times$ $n$ companion matrix of the relevant linearized forecast model, ${ }^{10}$ and the superscript " $\mathrm{e}$ " denotes forecasts conditioned on the lagged information set, $z_{t-1}$.

If $p_{t}^{*}$ is the $*^{t h}$ element of $z_{t}$, multiperiod price trend predictions of the forecast model in 5 are denoted by

$$
p_{t+j}^{* e}=\iota_{*}^{\prime} H^{j+1} z_{t-1}
$$

where the $n \times 1$ selector vector, $\iota_{*}$, has a one in the $*^{\text {th }}$ element and zeroes elsewhere.

Next, forecasts from 6 are substituted into the decision rule 4 to give

$$
\begin{aligned}
\Delta p_{t} & =A(1)\left[A(B) \sum_{i=0}^{\infty} \iota_{*}^{\prime}(\lambda B H)^{i} H z_{t-1}-p_{t-1}\right], \\
& =A(1)\left[A(B) \sum_{j=0}^{\infty}(\lambda B)^{j} \iota_{*}^{\prime}\left(z_{t-1}+\sum_{i=0}^{\infty}(\lambda B H)^{i}[H-I] z_{t-1}\right)-p_{t-1}\right], \\
& =-A(1)\left(p_{t-1}-p_{t-1}^{*}\right)+A(1) \iota_{*}^{\prime}[I-\lambda B H]^{-1}[H-I] z_{t-1}, \\
& =-A(1) \epsilon_{t-1}+S_{t}^{1}\left(\lambda B, \Delta p^{*} \mid H\right) .
\end{aligned}
$$

In the last line of 7 , the regressor in the first term on the right hand side of the equal sign is the standard notation for the error correction term in the trend deviation, $\epsilon_{t-1}=p_{t-1}-p_{t-1}^{*}$. The second term, $S_{t}^{1}(. \mid H)$, is a compact reference to the discounted forecasts of expected forward changes in the target path, $\Delta p_{t+i}^{*}$, that are conditioned on the forecast model in $5 .{ }^{11}$

Another important way to interpret the second term in the last line of equation 7 is to rewrite it as the inner product of a restricted coefficient vector, $h_{*}$, and the producers' information set, $S_{t}^{1}()=.h_{*}^{\prime} z_{t-1}$. Note from the third line in 7 that the $n \times 1$ coefficient vector, $h_{*}$, is completely defined by the adjustment cost parameter, $\lambda$, the discount factor, $B$, and the $H$ coefficients of the

\footnotetext{
${ }^{10}$ As illustrated in Swamy and Tinsley [1980] and Harvey [1989], companion matrices are a convenient tool for rewriting a system of high-order ARMA equations in a first-order format. In the case of a multivariate pth-order VAR, $x_{t}=\sum_{i=1}^{p} A_{i} x_{t-i}$ (where the $A_{i}$ are $q \times q$ matrices), the companion matrix is

$$
H=\left[\begin{array}{cccc}
A_{1} & A_{2} & \ldots & A_{p} \\
& I_{p q-q} & & 0_{q}
\end{array}\right] .
$$
}

\footnotetext{
${ }^{11}$ Assuming the relevant VAR forecast model is expressed in levels, the second and third lines of equation 7 contain the term $[H-I]$ to obtain forecasts of target price differences, $\Delta p_{t+i}^{*}$.
} 
forecast model in 5. This is a very transparent way of showing the effect of the overidentifying restrictions that are imposed under rational expectations (RE) by the forecast model in 5 on the coefficients of the rational error correction rule in 7 . By contrast, in a conventional error correction regression, the coefficients associated with regressors in the agents' information set, $z_{t-1}$, are unrestricted. $^{12}$

An estimate of the two-root decision rule 7 for the aggregate manufacturing price is shown in the first row of table II. Although this simple equation provides a respectable $R^{2}$ of .40 , there are two problems with this equation. First, the estimated residual is heavily autocorrelated, as indicated by a p-value of .00 for the Breusch-Godfrey statistic in the column labeled $B G(12)$. Second, the next column to the right in table II reports the p-value of a likelihood ratio test that adds the VAR model regressors of the price trend as unrestricted regressors; this test rejects the rational expectations (RE) restrictions imposed by the VAR forecast model at a p-value of .00. To save space, we do not show the results of applying the standard two-root adjustment model to every industry but essentially the same problems are encountered for all industries. In any case, it is shown below that the standard two-root model is nested in the more general model of frictions presented in the next subsection.

\section{Rational pricing under quadratic costs of adjusting moving averages.}

Both of the empirical deficiencies noted for the first equation in table II can be eliminated by relaxing the restriction that agents are subject only to costs of adjusting the current levels of industry prices. While maintaining the quadratic expansion characteristic of symmetric cost functions, polynomials in the lag operator can provide less restrictive approximations of adjustment cost functions and lead to natural interpretations of higher-order Euler equations.

One generalization of the quadratic adjustment cost terms in criterion 2 is to allow friction penalties to apply not only to changes in the price level but also to changes in any kth-order difference associated with producer smoothing of industry inflation rates or higher-order differences. $^{13}$

$$
p_{t}=\operatorname{argmin}\left(E_{t}\left\{\sum_{i=0}^{\infty} B^{i}\left[b_{0}\left(p_{t+i}-p_{t+i}^{*}\right)^{2}+\sum_{k=1}^{m} b_{k}\left((1-L)^{k} p_{t+i}\right)^{2}\right]\right\}\right) .
$$

\footnotetext{
${ }^{12}$ In the empirical estimates shown in the tables, the relevant industry VAR forecast model contains four quarterly lags of the input price arguments of the industry price trend, $p_{t}^{*}$. Methods of estimating the rational error correction decision rules described in this section are discussed in Tinsley [1993].

${ }^{13}$ Signalling conventions in oligopolistic markets or instrument uncertainty regarding customer responses to price behavior may motivate smoothing of both levels and derivatives of prices. In a similar vein, Greenwald and Stiglitz [1989] note "price rigidities appear to exist to a greater extent regarding past rates of change (i.e. inflation inertia) rather than past levels (i.e. pure price level inertia)" (p.364).
} 
Another generalization is to extend the quadratic adjustment costs in criterion 2 from one-period changes in the price level, $(1-L) p_{t+i}$, to changes in moving averages, (1 L) $\sum_{j=0}^{k-1} p_{t+i-j}=\left(1-L^{k}\right) p_{t+i}$, such as might be associated with seasonal or term contracts.

$$
p_{t}=\operatorname{argmin}\left(E_{t}\left\{\sum_{i=0}^{\infty} B^{i}\left[b_{0}\left(p_{t+i}-p_{t+i}^{*}\right)^{2}+\sum_{k=1}^{m} b_{k}\left(\left(1-L^{k}\right) p_{t+i}\right)^{2}\right]\right\}\right) .
$$

Under either of these extended criteria, the format of the associated Euler equation of the optimal price path is exactly the same as that shown earlier in the Euler equation 3 for the standard criterion $2 .{ }^{14}$ However, the order of the factor polynomial, $A(L)$, may now exceed one, $m \geq 1$, where $A(L)=\left(1+a_{1} L+a_{2} L^{2}+\ldots+a_{m} L^{m}\right)$. Thus, instead of two roots, $\lambda$ and $(\lambda B)^{-1}$, the Euler equation now contains $m$ pairs of roots where each pair is reciprocal about the discount factor, $B .{ }^{15}$

The derivation of the optimal decision rule associated with either criterion $2^{\prime}$ or criterion $2^{\prime \prime}$ proceeds similarly to the procedure shown earlier in equations 4 through 7 for the standard case where $A($.$) is a first-order polynomial. The generalization of the rational error correction format is$

$$
\Delta p_{t}=-A(1) \epsilon_{t-1}+A^{*}(L) \Delta p_{t-1}+S_{t}^{1}\left(G, \Delta p^{*}\right) .
$$

As in the two-root decision rule in 7, the coefficient of the error correction term, $\epsilon_{t-1}$, continues to be defined as the negative sum of coefficients in the factor polynomial, $-A(1)$. However, the remaining terms are different and have two important consequences for the dynamic specification of the optimal pricing rule.

First, autoregressive lags of the industry price may now appear as regressors in the rational error correction decision rule 8 , with coefficients denoted by the $A^{*}(L)$ component polynomial. The latter is the $(m-1)$-order polynomial obtained by rewriting the $m$-order lag polynomial in a level and difference format, $A(L) \equiv A(1) L+\left(1-A^{*}(L) L\right)(1-L) .{ }^{16}$

\footnotetext{
${ }^{14}$ The Euler equation for $2^{\prime}$ is: $E_{t}\left\{b_{0}\left(p_{t}-p_{t}^{*}\right)+\sum_{k=1}^{m} b_{k}[(1-L)(1-B F)]^{k} p_{t}\right\}=0$ and the Euler equation for $2^{\prime \prime}$ is: $E_{t}\left\{b_{0}\left(p_{t}-p_{t}^{*}\right)+\sum_{k=1}^{m} b_{k}\left[\left(1-L^{k}\right)\left(1-B^{k} F^{k}\right)\right] p_{t}\right\}=0$. Because these Euler equations are symmetric in $L$ and $B F$, each has the factor polynomial representation shown in equation 3, vid. Tinsley [1993].

${ }^{15}$ Another example of a higher-order Euler equation that is a special case of the moving-average smoothing in criterion $2^{\prime \prime}$ is the example of staggered contracts, Taylor [1980], where some agents negotiate a 1-period contract, some a 2-period contract, others a 3-period contract, and so on. Ignoring discounting, denote the aggregate of new contracts formulated in period $t$ by $x_{t}^{c}=E_{t}\left\{A(1) A(F)^{-1} x_{t}^{*}\right\}$ and the associated aggregate of all existing contracts in $t$ as $x_{t}=A(1) A(L)^{-1} x_{t}^{c}$, where $A($.$) is an m-order polynomial that approximates the expiration schedule of contracts.$ Substituting out the contract prices yields the Euler equation 3 for $B=1: E_{t}\left\{A(F) A(L) x_{t}-A(1)^{2} x_{t}^{*}\right\}=0$.

${ }^{16}$ The coefficients of $A^{*}($.$) are simple moving sums of the coefficients of A($.$) . To illustrate, if a=\left[a_{1}, a_{2}, \ldots, a_{m}\right]^{\prime}$ is the $m \times 1$ vector of the unknown parameters in the $A($.$) polynomial and \theta=\left[A(1), a_{1}^{*}, a_{2}^{*}, \ldots, a_{m-1}^{*}\right]^{\prime}$ is the vector of transformed parameters, then $\theta=\iota_{1}+T a$, where $\iota_{1}$ is an $m \times 1$ vector with one in the top element and zeroes elsewhere, and $T$ is an $m \times m$ transformation matrix with all elements on and above the main diagonal equal to one and zeroes elsewhere.
} 
Second, forecasts of future changes in the trend price are now discounted by multiple discount factors. As in the standard two-root case, the forward-looking term in the optimal decision rule can still be written as the inner product of a restricted coefficient vector, $h_{*}$, times the producers' information vector, $S_{t}^{1}\left(G, \Delta p^{*}\right) \equiv h_{*}^{\prime} z_{t}$. As one might expect in the case of higher-order Euler equations, derivation of the vector, $h_{*}$, is more complicated but the essential role of overidentifying restrictions imposed by the parameters, $H$, of the VAR forecast model remains the same. However, instead of discounting the forecasts of forward changes in the trend price by the single root, $\lambda B$, forecasts are now discounted by the $m$ roots of the lead polynomial, $A(B F)$. As indicated by the notation in the last term of equation 8 , these $m$ roots are contained in the matrix, $G .{ }^{17}$

An empirical example of the more general specification of dynamic adjustment in the rational error correction decision rule of equation 8 is shown for the manufacturing price in the second line of table II. The column headed by lag indicates the estimated order of the $A(L)$ polynomial factor. In the case of the second line, the lag order is three $(m=3)$ indicating that two autoregressive terms, $\Delta p_{t-1}$ and $\Delta p_{t-2}$, are significant as additional regressors. The three roots of $A(L)$ are used also to compute the three discount factors used to weight the VAR forecasts of future target price changes in $S_{t}^{1}($.$) . In contrast to the statistical problems exhibited by the two-root decision rule$ in the first line of table II, the six-root decision rule in the second line does not exhibit residual autocorrelation (the p-value is .31) and the RE restrictions imposed on the decision rule by the VAR target price forecasts are now accepted.

The remaining rows of table II show the results of applying the extended error correction decision rule in 8 to the prices of SIC two-digit industries. Generally, all industries show significant error correction to the gap deviation from the target price; the order of the factor polynomial, $A(L)$, always exceeds one, ${ }^{18}$ and rational expectations (RE) restrictions are accepted for all industries.

The last column in table II measures the change in the $R^{2}$ that is due to the presence of the forward-looking expectations term, $S_{t}^{1}($.$) . For the standard two-root pricing rule in the first line$ of table II, the entry is .36 indicating that removing forward-looking expectations, $S_{t}^{1}($.$) , lowers$

${ }^{17}$ As derived in Tinsley [1993], the closed-form solution of the restricted coefficient vector is now

$$
h_{*}=A(1) A(B)\left(\iota_{m}^{\prime}[I-G]^{-1} \otimes\left[H^{\prime}-I\right]\right)\left[I-G \otimes H^{\prime}\right]^{-1}\left(\iota_{m} \otimes \iota_{*}\right),
$$

where $\iota_{m}$ is an $m \times 1$ vector with a one in the bottom element and zeroes elsewhere; $\otimes$ denotes the Kronecker product; and the $m \times m$ matrix $G$ is a companion matrix of the forward polynomial, $A(B F)$,

$$
G=\left[\begin{array}{cccc}
0 & & I_{m-1} & \\
-a_{m} B^{m} & -a_{m-1} B^{m-1} & \cdots & -a_{1} B
\end{array}\right] .
$$

\footnotetext{
${ }^{18}$ Although seasonal variations are small in most producer prices, Beaulieu and Miron [1990], and seasonal dummies are included, the polynomial order for several industries suggests seasonal responses.
} 
the $R^{2}$ by an order of magnitude, from .40 to .04 . However, in the second line of table II, after allowing for the more complicated frictions suggested by the manufacturing price autocorrelations, the incremental $R^{2}$ attributable to forward expectations is only .01 points or about $1 \%$ of the total $R^{2}$ of .72. The remaining entries in the last column of table II indicate that the proportions of sample variation explained by forward-looking expectations are often modest after accounting for higher-order adjustment costs.

Having discussed, in this section, the estimation of baseline models of rational symmetric pricing with reasonable statistical properties, we turn next to tests of possible sources of asymmetries in producer pricing.

\section{SOURCES OF ASYMMETRIES IN PRODUCER PRICING}

This section first explores the possibility that asymmetric pricing may be largely attributed to asymmetric movements in output. The second subsection examines an alternative conjecture that pricing asymmetries are due to state-conditional shifts in the parameters of linear pricing rules.

\section{Price responses to industry output gaps.}

Given the results in table I that there appear to be asymmetric movements in the output gaps of many industries, we first explore the obvious possibility that asymmetries in industry prices may reflect price responses to asymmetric industry output gaps. In the case of the industry target price, $p^{*}$, it seems plausible that either marginal cost or the desired price markup may vary with the rate of industry utilization. The sign of the price response may be either positive or negative, because marginal costs may increase or decrease with rising utilization rates. Also, margins may vary procyclically or countercyclically, depending on boom or bust variations in the price elasticity of demand or in the perceived return to defections from collusive pricing strategies.

A limitation of estimating the industry trend price, $p_{t}^{*}$, by cointegration is that only I(1) arguments of the price targets are identified. Because industry utilization rates are $\mathrm{I}(0)$ or stationary, as noted earlier, the influence of utilization rates on industry target prices cannot be captured by cointegration and the forcing term of the Euler equation 3 must be directly altered:

$$
E_{t}\left\{A(L) A(B F) p_{t}-A(1) A(B)\left[p_{t}^{*}+D(L) u_{t}\right]\right\}=0
$$

Here, we retain the notational convention that $p^{*}$ denotes the portion of the target price that is captured by cointegration regressions. The additional term in the revised Euler equation $3^{\prime}$ applies a lag polynomial, $D(L)$, to the industry utilization rate to allow for the possibility that the industry target price may be influenced also by recent trend deviations in output.

Once again multiplying the Euler equation by the inverse of the lead polynomial, $A(B F)^{-1}$, 
and rearranging gives the revised decision rule

$$
\begin{aligned}
\Delta p_{t} & =-A(1) \epsilon_{t-1}+A^{*}(L) \Delta p_{t-1}+h_{*}^{\prime} z_{t-1}+E_{t}\left\{A(1) A(B) A(B F)^{-1} D(L) u_{t}\right\}, \\
& =-A(1) \epsilon_{t-1}+A^{*}(L) \Delta p_{t-1}+h_{*}^{\prime} z_{t-1}+D(L)\left[h_{u}^{\prime} z_{t-1}\right] .
\end{aligned}
$$

Rational forecasts of forward industry utilization rates in the second line of 9 are obtained by applying a restricted coefficient vector, $h_{u}$, to the information set contained in $z_{t-1}{ }^{19}$ For the equations presented here, four-quarter autoregressions in the industry utilization rates are used to generate forward utilization forecasts. $D(L)$ is arbitrarily set to a first-order polynomial, the minimum order that allows us to distinguish between transient price level responses to output gaps, $D(1)=0$, and persistent level responses, $D(1) \neq 0$.

The first few columns in table III provide several of the key statistics reported in table II, such as the level and difference decomposition of the factor polynomial, $A(L)$. The statistics may vary slightly from those in table II because these are the final equations that include either estimated price responses to output gaps or asymmetric responses to lagged price gaps (discussed in the next subsection) or both.

Two statistics for utilization rate regressors are reported in table III in the columns headed by output gap effects. The first is the p-value of a likelihood ratio test for adding the industry output gap regressors in the RE format required by equation 9 . A p-value less than 10 indicates a significant price response to utilization rates. For example, the first line for manufacturing indicates that manufacturing utilization is a significant determinant of manufacturing prices, with a p-value of .03. As shown in the remainder of this column, utilization rate forecasts are significant in about a third of the industries. Generally, this occurs in industries with relatively homogeneous products, such as textiles (SIC 22) or motor vehicles SIC 371), where an aggregate industry capacity concept may be more applicable.

The second statistic is the sum of the estimated weights, $D(1)$, on lags of the present-value of expected utilization rates. The sum of estimated weights for manufacturing is small (and statistically insignificant), indicating any persistent level effect on industry prices from higher or lower utilization rates is modest.

The result most relevant for analysis of pricing asymmetries is that the weight sum is positive for all industries except motor vehicles. This is the traditional sign expected for capacity bottleneck pressure on industry pricing. However, positive price responses cannot transform negative gap

\footnotetext{
${ }^{19}$ The closed-form solution of the coefficient vector for RE forecasts of utilization rates is $h_{u}=A(1) A(B)\left[\iota_{m}^{\prime} \otimes H^{\prime}\right]\left[I_{n m}-G \otimes H^{\prime}\right]^{-1}\left(\iota_{m} \otimes \iota_{u}\right]$
}

where $\iota_{u}$ denotes the selector vector for $u_{t}$ in $z_{t}$. 
asymmetries in outputs into positive gap asymmetries for prices. Thus, output asymmetry is unlikely to be the source of the positive gap asymmetry noted for industry prices in section II.

Asymmetric pricing due to state-conditional adjustments.

Having taken account of industry price responses to trend deviations in industry output, we now turn to the nature of price responses to the trend deviations of prices. That is, in contrast to the usual cyclical analysis of pricing which is geared to output deviations from trend, it seems plausible that price trend deviations themselves might be a promising indicator of potential asymmetries in adjustments to price trends. Given direct measurements of price trend deviations, a tractable analysis is to determine if the roots of the factor polynomials are different when the price is above trend, $\epsilon_{t-1}>0$, or below, $\epsilon_{t-1}<0$.

Initial experimentation with the estimated decision rules of all industries indicated that any detectable switching effect would be confined to a sign split only on the error correction response, $A(1)$. The intuition for this attractive simplification can be seen by examining the structure of the error correction decision rule for the two-root case, which is restated here as

$$
\Delta p_{t}=-A(1) \epsilon_{t-1}+A(1) A(B)^{-1} S_{t}\left(\lambda B, \Delta p^{*}\right) .
$$

In contrast to the null hypothesis of symmetric adjustment, the alternative suggested by the results in table I is that price adjustment speed is slower when the price is above trend. In other words, when the price gap is positive, the root of the factor polynomial moves towards unity, driving the error correction response, $A(1) \equiv(1-\lambda)$, toward zero. However, the remaining term in equation 10 is relatively insensitive to moderate increases in $\lambda$. First, the present-value summation, $S_{t}($.$) , whose weights sum to one, is unlikely to vary much with moderate increases in the effective$ discount rate, $\lambda B$, which has an upper bound of $B$. Second, for discount factors, $B$, near unity, the effective coefficient, $A(1) / A(B)$, of the present-value sum is approximately one and also insensitive to variations in $\lambda$.

The first two columns in table III under the heading asymmetric price gap effects list the p-values of two tests for asymmetric error correction responses of industry prices to signed patterns of the price gaps. The estimated price response to a positive price gap, $\epsilon_{t-1}^{+}$, is significantly different from the estimated response to a negative price gap, $\epsilon_{t-1}^{-}$, if the p-value in the column headed by $L R\left(\epsilon_{t-1}^{+}, \epsilon_{t-1}^{-}\right)$, is .10 or less. This test suggests asymmetric error correction responses are significant in total manufacturing and in about $40 \%$ of the SIC two-digit industries. In all cases, the coefficient of the positive price gap is significantly smaller than the coefficient of the negative price gap, indicating a positive skew in price adjustments. In fact, the coefficient of the positive price gap in these industries, shown in the column headed by $A^{+}(1)$, is also not significantly different 
from zero, suggesting the absence of systematic error correction when price is above trend.

A statistically zero response to positive price gaps also appeared in several of the remaining industries. This asymmetric error correction response pattern is not reliably detected by the first likelihood ratio if the sampling error of the estimated coefficient of the positive price gap is sufficiently large to encompass both zero and the coefficient estimated for the negative price gap. Consequently, a second test is applied to specifically test for nominal ratcheting where there is no systematic price response by producers to positive price gaps. This pattern proved to be surprisingly pervasive; nominal ratcheting is rejected for only eight industries (when the p-value is .10 or less in the column headed by $\left.L R\left(0, \epsilon_{t-1}^{-}\right)\right)$.

The last two columns in table III provide estimates of mean lag responses to random shocks that are indicated by the estimated asymmetric responses, where $M L^{-}$denotes the mean lag response (in quarters) if the price gap is negative (industry price below trend) and $M L^{+}$is the approximate mean lag if the price is above trend. Only a single mean lag statistic is reported if the estimated industry price response is symmetric. ${ }^{20}$

As indicated in the first row of table III, the mean lag response to shocks in manufacturing is about two quarters if the aggregate price index is below trend, $M L^{-}=1.8$, and about six quarters if the price is above trend, $M L^{+}=6.2$. The substantial disparity between the mean lag responses reported for many of the industries indicates that asymmetric pricing is not just an econometric curiosity but implies economically meaningful variations in the average response times of industry prices. Depending on whether prices are above or below trend, mean lags in industry price responses can differ by as much as an order of magnitude.

In summary, the evidence presented in this section supports the conjecture of section II that producers are more reluctant to reduce positive trend deviations in prices than to eliminate negative deviations. However, it is unsatisfying, if not tautological, to conclude that the perceived costs of reducing prices are simply larger than the costs of price increases. Modelling intertemporal decision rules is a useful strategy to distinguish dynamic responses of agents from the background motion of conditioning variables (such as predetermined forcing terms) but it does not provide insights into the market or institutional constraints on agents that lead to asymmetric responses. The next section examines several theories of asymmetric pricing and attempts to match predictions of these interpretations against characteristics of producers with asymmetric pricing.

\footnotetext{
${ }^{20}$ Mean lags are estimated by $\left[1-A^{ \pm}(1)-A^{*}(1)\right] / A^{ \pm}(1)$. As noted in table III, mean lags for positive price gaps are approximate for industries with nonpositive estimates of $A^{+}(1)$. Of course, given the forward-looking role of the polynomial lead operator, $A(B F)^{-1}$, the "mean lag" for anticipated events approaches zero as the discount factor, $B$, approaches one.
} 


\section{THEORIES OF POSITIVE ASYMMETRIES IN PRICING}

Four theories of asymmetric pricing are reviewed and a central feature of each theory is selected to provide an indicator of the propensity for asymmetric pricing. The second subsection discusses correlations of these indicators with the industry pricing asymmetries presented in section IV. Two interpretations have moderate empirical support.

\section{Four indicators of alternative theories}

(1) Strategic pricing and the Herfindahl (HF) indicator. A key finding of table III is that many producers are relatively quick to raise prices that fall below trend but are slower to reduce prices that are above trend. The most venerable explanations of positive asymmetries in pricing are those based on implicit price collusions by oligopolistic competitors, even in protracted intervals of depressed demand. Early examples include the inverse association suggested by Means [1935] between industry concentration and the frequency and size of price adjustments. There are also several modern theoretical variations of oligopolistic pricing strategies which predict countercyclical movements in price margins over cost, such as Rotemberg and Saloner [1986]. Following a popular convention in empirical industrial organization literature, the Herfindahl index of the sum of squared market shares, HF, is used as an indicator of the competitive structure of an industry. The indexes for SIC two-digit industries are constructed from the 1982 Census of Manufactures.

(2) Wage inertia and the labor compensation share $(L S)$ indicator. Another early interpretation of asymmetry links the cyclical behavior of prices to asymmetric movements of unit costs, principally nominal wages. A well-known example is the suggestion by Keynes [1936] that employees may resist reductions in nominal wages because it is difficult for atomistic agents to coordinate their actions.

Although downward stickiness of nominal wages was originally suggested to motivate the countercyclical movements in real wages required by neoclassical production functions, postwar time series evidence suggests that industry real product wages are largely acyclical, Barsky and Solon [1989]. Acyclical behavior in real wages is not inconsistent with nominal ratcheting in both wages and prices. To indicate the potential influence of resistance to downward movements in labor compensation costs, the labor share of gross output, LS, is used to indicate those industries where the purchase of labor inputs is a major component of operating costs. The labor share of gross industry output, adjusted to remove the effect of indirect taxes, is obtained from the U.S. Commerce 1982 input-output system.

(3) Instrument uncertainty and a liquid asset (LA) indicator. Greenwald and Stiglitz [1989] apply the analysis by Brainard [1967] of instrument uncertainty to suggest a tendency for producers to rely more on quantity adjustments than price adjustments over the business cycle. The basic 
elements are that producers are risk averse and that price adjustments are perceived to be more risky than quantity adjustments.

Originally advanced to interpret the (symmetric) inertia of producer prices, this theory can be modified to explain positive asymmetry in producer prices by adding an asymmetry due to costs of illiquidity. This altered conjecture has two essential ingredients: (i) the profit variance associated with price changes is significantly larger than the variance effects of output changes; and (ii) producer risk varies countercyclically due to imperfect credit markets. Under the first condition, costs associated with altered production, such as worker hires or layoffs, are relatively predictable but the profit implications of price changes are more uncertain due to unpredictable customer or competitor responses.

Under the second condition, risk-neutral firms confronting imperfect credit markets will prefer self-financing and seek to avoid the costs of bankruptcy or technical insolvency which can trigger restrictive covenants imposed by creditors. In boom periods with large accumulations of retained earnings, the probability of exhausting internal liquid asset reserves is small; little weight is placed on the risk exposure associated with price variations and both price and output are varied to maximize the discounted stream of expected profits. However, in bad times, self-financing protection is inevitably eroded by drains on liquid asset buffer stocks, and there is greater concern about the uncertainty of projected receipts and maintenance of cash flows. Producers become more cautious about changing prices to alter expected sales and respond to reduced demand prospects by scaling back the rate of planned production.

The ratio of liquid assets to the capitalized value of earnings, LA, appears to be an appropriate indicator of a preference for self-financing. ${ }^{21}$ Note that we are not interested in historical movements of industry liquid asset ratios but the cross-industry ranking as a guide to the average self-financing protection selected by industries. Liquid assets are defined as cash and securities plus inventories less short-term debt; industry data is obtained from the U.S. Department of Commerce's 1982 Quarterly Financial Report for manufacturing.

(4) Expected inflation and a trend inflation (TI) indicator. The fourth interpretation of asymmetric pricing is based on the direct costs of changing nominal prices. As outlined in Tsiddon [1993] and Ball and Mankiw [1994], if menu costs are associated with price changes, a positive expected drift in the industry price trend will induce asymmetric price responses where producers are relatively quick to close negative price gaps but slower to reverse positive price

\footnotetext{
${ }^{21}$ As in Tinsley [1970a], using a simplifying assumption that earnings in each period are independently distributed and accumulated over a planning horizon, the probability of exhausting liquid asset reserves is exponentially declining in the ratio of initial reserves to expected earnings divided by the squared coefficient of variation of earnings. Given imperfect access to credit markets, firms in industries with more volatile earnings will hold higher liquid asset reserves, on average, to met a given probability of technical insolvency. Because equity earnings are highly volatile from period to period, expected earnings are replaced by the capitalized value of average earnings.
} 
gaps.

A consequence of fixed (or proportional) costs associated with price actions is that a zone of price inaction is placed about the current price. Duration in the inaction zone will depend on the motion of the trend price. The larger the variability of trend price changes, the shorter will be the interval of time before either the upper or lower boundary of the inaction zone is crossed by the price trend, triggering a price response by the producer. Higher expected inflation of the trend price will increase the probability that the trend price will first reach the upper boundary rather than the lower boundary. When price is above trend, passive reversal of the positive price gap by the motion of the trend price may be preferred to price adjustment due to the cost of direct price action.

Thus, in a menu cost interpretation of positive asymmetry in producer pricing, the probability of active price adjustment will vary directly with the variability of the trend price and inversely with the rate of expected inflation in the trend. The inverse of the coefficient of variation of trend price inflation is selected as the indicator of this theory, where the trend inflation, TI, indicator is the ratio of the mean to standard deviation of the four-quarter inflation rate of the industry price trend.

\section{Cross-industry contrasts of alternative theories}

Two empirical screening tests of the alternative interpretations of asymmetric pricing, as represented by the four selected indicators, are presented in table IV. Each test is based on the hypothesis that a successful indicator will be positively correlated with the extent of asymmetry in industry pricing.

The first test contrasts group means of each indicator where the average value of each indicator is expected to be larger in the group of industries that exhibit asymmetric pricing than in the group of industries with symmetric pricing behavior. The first row of table IV lists the average indicator values in the eight industries with symmetric pricing (as classified in table III). The indicator averages in the thirteen industries with asymmetric pricing are shown in the second row of table IV. The average indicator value is always larger for the asymmetric pricing industries, although barely so for the Herfindahl indicator, HF.

The statistical significance of differences in the group means of the indicators is evaluated by the p-values in the third and fourth rows of table IV. In the case of equal variances in the two industry groupings (the third row), the industry group means of the Herfindahl indicator are not significantly different but the means of the remaining indicators are significantly larger in the asymmetric pricing group at significance levels that exceed $90 \%$ (p-value less than .10). When the null hypothesis allows for differences in the variances of the two industry groupings (the fourth row), the statistical support of the labor share, LS, and liquid asset, LA, indicators is weaker with 
p-values above .10 .

The second set of screening tests in table IV uses regression analysis to estimate the degree of positive association between indicator values and a measure of the extent of asymmetry in industry pricing. The sample for the regressions is the cross-section of industries in the group that exhibited asymmetric pricing. The dependent variable of each cross-section regression is an index of asymmetric pricing, $M L^{+} / M L^{-}$, defined as the ratio of the industry mean lag responses to positive and negative price gaps shown in table III.

The fifth row of table IV displays the bivariate correlations of the asymmetric pricing index with the relevant industry indicator. The significance of the correlations is indicated by t-ratios in parentheses. The asymmetric pricing index is most strongly correlated with the liquid asset ratio, LA, and the trend inflation indicator, TI, where both correlations are moderately strong and have significance levels well above $90 \%$.

The approach in the next row of table IV is to provide an adjustment for possible sampling errors in the cross-industry indicators. All indicators, except for the trend inflation indicator, TI, are based on industry values in a given year (1982). On the assumption that the cross-industry ranks of these indicators are more likely to be invariant to any sampling errors associated with cardinal measurements drawn from a single year, the industry ranks of the indicators are used as the relevant regressors in the sixth row of table IV. The major casualty of this adjustment is the Herfindahl indicator, HF.

Because it is unlikely that there is only a single explanation of asymmetries in industry pricing, the last two rows of table IV employ multivariate regressions in an attempt to parse the explained variation in the asymmetric index among competing indicators. The explanatory power of the multiple indicator regressions is little affected by retaining only the liquid asset indicator, LA, and the trend inflation indicator, TI, as regressors, as shown in the last row of table IV. The liquid asset indicator remains statistically significant with a p-value less than .10 , whereas the p-value of the coefficient of the trend inflation indicator is about .15. Bounds on the explanatory contributions of the indicators can be established by comparing the $R^{2}$ of the last equation in table IV with the squares of the simple correlations in the fifth row. This contrast suggests that the liquid asset indicator, LA, may be explaining from $20 \%$ to $36 \%$ of the total cross-industry variation in asymmetric pricing, and the trend inflation indicator, TI, may contribute from $12 \%$ to $28 \%$ of the cross-industry variation. 


\section{CONCLUDING COMMENTS}

This paper provides evidence to support two stylized facts: Production in many manufacturing industries exhibits negative asymmetry, where shortfalls from trend output are larger, on average, than positive trend deviations. By contrast, positive asymmetry is more common in producer pricing where positive trend deviations are more persistent than the deviations of prices below unit cost trends.

Reasons for these asymmetries in producer responses and the nature of causal interactions between output and price asymmetries are not resolved in this paper. Although two interpretations, menu costs and instrument uncertainty, are supported by the simple cross-industry regressions in the preceding section, this is only suggestive evidence at best. These two candidate theories have very different implications for interpreting producer behavior and for the design of stabilization polices.

Under menu costs, expected inflation is a source of asymmetric pricing responses to shocks. The deadweight loss of inefficient sectoral allocations due to asymmetric price adjustments will diminish at lower rates of expected inflation. Indeed, if menu costs are symmetric and aggregate inflation is the sole source of expected drift in industry target prices, this source of asymmetry in producer pricing will vanish if the expected rate of aggregate inflation is zero.

However, the complication raised in the preceding section is that expected inflation is probably not the sole cause of asymmetric pricing. Another plausible determinant is instrument uncertainty where the preferred producer response to unfavorable shocks may be output contraction rather than price adjustment. If the choice between output or price responses is influenced by the internal liquidity of firms then the sacrifice ratios of disinflation policies may depend on the cyclical timing

of policy. ${ }^{22}$ Asymmetric reliance by producers on output responses to reduced demand is also consistent with concave industry supply functions, where negative output gaps are accompanied by little or no change in price but output expansions above preferred operating rates may be paired with large changes in prices. Stabilization polices will increase average output if the supply of output is a concave function of price. ${ }^{23}$

Any source of positive price asymmetry may induce negative asymmetries in output, not only in the same industry through downward sloping demand schedules but also in other industries through aggregate demand spillover effects of reduced expenditures on material and labor inputs. However, the instrument uncertainty interpretation suggests that producers respond to unfavorable

\footnotetext{
${ }^{22}$ State-conditional aggregate effects of monetary policy are not always cleanly linked with the existence of state-dependent producer pricing rules; compare the flexible aggregate price responses in Caplin and Spulber [1987] with the state-dependent real output effects in Caplin and Leahy [1991].

${ }^{23}$ Denoting the supply of output at a given price by $Q(P)$, supply is concave in $P$ if $Q($.$) lies on or below a tangent$ at the average price, $E\{P\}$. It follows, by Jensen's inequality, that $Q(E\{P\}) \geq E\{Q(P)\}$.
} 
shocks with output adjustments in place of price responses. This implies that negative output asymmetry should be matched with positive pricing asymmetry within the same industry. Although the reductions or reversals of negative asymmetry in the nominal outputs of industries discussed in section II are suggestive, the possibility of matched asymmetries in price and production (or employment) decision rules would appear to be a useful topic for future research.

Finally, to underscore the risks of sharp priors on the order of Euler equations, we note that the empirical models of producer pricing strongly reject the nested specification that price dynamics are due only to costs of adjusting price levels. The results for both symmetric and asymmetric responses indicate that the traditional two-root Euler equation description of dynamic pricing requires ad hoc empirical fixes, including autocorrelated errors and non-rational expectations. No ad hoc adjustments appear to be necessary if the specification of frictions is relaxed to accommodate producer incentives to smooth moving averages of prices and rates of inflation.

\section{REFERENCES}

Ball, L. and G. Mankiw. “Asymmetric Price Adjustment and Economic Fluctuations.” Economic Journal, 104, March 1994, 247-61.

Barsky, R. and G. Solon. "Real Wages Over the Business Cycle." NBER Working Paper Series, 2888, March 1989.

Beaulieu, J. and J. Miron. “The Seasonal Cycle in U.S. Manufacturing.” NBER Working Paper Series, 3450, September 1990.

Blinder, A. "Why are Prices Sticky? Preliminary Results From an Interview Study." American Economic Review, 81(2), May 1991, 89-96.

Brainard, W. "Uncertainty and the Effectiveness of Policy." American Economic Review, May 1967, 411-25.

Calvo, G. "Staggered Prices in a Utility-Maximizing Framework." Journal of Monetary Economics, 12(3), September, 1983, 383-98.

Canova, F. "Detrending and Business Cycle Facts." CEPR Discussion Paper 782, June 1993.

Caplin, A. and D. Spulber. "Menu Costs and the Neutrality of Money." Quarterly Journal of Economics, 102, November 1987, 703-26.

Caplin, A. and J. Leahy. "State-Dependent Pricing and the Dynamics of Money and Output." Quarterly Journal of Economics, 156(3), August 1991, 683-708.

Carlton, D. “The Rigidity of Prices.” American Economic Review, September 1986, 637-58.

Christiano, L. M. Eichenbaum, and C. Evans. "Identification and the Effects of Monetary Policy Shocks." Federal Reserve Bank of Chicago Working Paper 94-7, May 1994.

DeLong, B. and L. Summers. “Are Business Cycles Symmetrical?" in The American Business Cycle, edited by R. Gordon. Chicago: The University of Chicago Press, 1986, 166-79.

Falk, B. "Further Evidence on the Asymmetric Behavior of Economic Time Series over the Business Cycle." Journal of Political Economy, 94(5), October 1986, 1096-109.

Friedman, M. “The 'Plucking Model' of Business Fluctuations Revisited.” Economic Inquiry, 31, April 1993, 171-7. 
Goodwin, T. and R. Sweeney. "International Evidence on Friedman's Theory of the Business Cycle." Economic Inquiry, 31, April 1993, 178-93.

Gonzalo, J. and C. Granger. "Estimation of Common Long-Memory Components in Cointegrated Systems." Journal of Business and Economic Statistics, 13(1), January 1995, 27-35.

Greenwald, B. and J. Stiglitz. “Toward a Theory of Rigidities.” American Economic Review, 79, 1989, 364-9.

Haberler, G. Prosperity and Depression. Geneva: League of Nations, 1938.

Harvey, A. Forecasting, Structural Time Series Models, and the Kalman Filter. Cambridge: Cambridge University Press, 1989.

Harvey, A. and A. Jaeger. "Detrending, Stylized Facts, and the Business Cycle." Journal of Applied Econometrics, 8(3), July-September 1993, 231-47.

Hicks, J. A Contribution to the Theory of the Trade Cycle. Oxford: Clarendon Press, 1950.

Keynes, J. The General Theory of Employment, Interest and Money. London: Macmillan, 1936.

Lauer, G. and C. Han. "Power of Cochran's Test in the Behrens-Fisher Problem." Technometrics, 16(4), November 1974, 545-9.

McNevin, B. and S. Neftci. "Some Evidence on the Non-Linearity of Economic Time Series: 1890-1981," in Cycles and Chaos in Economic Equilibrium, edited by J. Benhabib. Princeton: Princeton University Press, 1991, 429-45.

McQueen, G. and S. Thorley. “Asymmetric Business Cycle Turning Points.” Journal of Monetary Economics, 31, June 1993, 341-62.

Means, G. "Price Inflexibility and the Requirements of a Stabilizing Monetary Policy." Journal of the American Statistical Association, 1935, 401-13.

Mitchell, W. Business Cycles. New York: National Bureau of Economic Research, 1927.

Neftci, S. “Are Economic Time Series Asymmetric Over the Business Cycle?” Journal of Political Economy, 92, April 1984, 307-28.

Nelson, C. and H. Kang. "Spurious Periodicity in Inappropriately Detrended Time Series." Econometrica, 49, 1981, 741-51.

Osborn, D. "Moving Average Detrending of Integrated Processes." University of Manchester, working paper, March 1993.

Raddock, R. "Revised Federal Reserve Rates of Capacity Utilization.” Federal Reserve Bulletin, 71, October 1985, 754-66.

Rotemberg, J. “Sticky Prices in the United States.” Journal of Political Economy, 90(6), December 1982, 1187- 211.

Rotemberg, J. "The New Keynesian Microfoundations," in NBER Macroeconomics Annual 1987, edited by S. Fischer. Cambridge: MIT Press, 1987, 69-104.

Rotemberg, J. and G. Saloner. "A Supergame-Theoretic Model of Price Wars During Booms." American Economic Review, 76(3), June, 1986, 390-407.

Sargent, T. "The Ends of Four Big Inflations," in Inflation: Causes and Effects, edited by R. Hall. Chicago: University of Chicago Press, 1982, 41-97.

Sichel, D. "Business Cycle Asymmetry: A Deeper Look.” Economic Inquiry, 31, April 1993, 224-36.

Sims, C. "Interpreting the Macroeconomic Time Series Facts." European Economic Review, 36(5), June 1992, 9751011.

Swamy, P. and P. Tinsley. "Linear Prediction and Estimation Methods for Regression Models with Stationary Stochastic 
Coefficients." Journal of Econometrics, 12(2), February 1980, 103-42.

Taylor, J. “Aggregate Dynamics and Staggered Contracts.” Journal of Political Economy, 88(1), February 1980, 1-23.

Tinsley, P. "Capital Structure, Precautionary Balances, and Valuation of the Firm: The Problem of Financial Risk." Journal of Financial and Quantitative Analysis, March 1970(a), 33-61.

Tinsley, P. “On Ramps, Turnpikes, and Distributed Lag Approximations of Optimal Intertemporal Adjustment." Western Economic Journal, December 1970(b), 397-411.

Tinsley, P. "Fitting Both Data and Theories: Polynomial Adjustment Costs and Error-Correction Decision Rules." FRB FEDS Working Paper 93-21, 1993.

Tobin, J. "Inflation and Unemployment.” American Economic Review, March 1972, 1-18.

Tsiddon, D. "The (Mis)Behavior of the Aggregate Price Level." Review of Economic Studies, 60(4), October 1993, 889-902.

Waterson, M. Economic Theory of the Industry. Cambridge: Cambridge University Press, 1984. 
Table I

Asymmetries in Industry Output and Price Trend Deviations ${ }^{a}$

\begin{tabular}{|c|c|c|c|c|c|c|c|}
\hline \multirow[b]{3}{*}{ industry } & \multirow[b]{3}{*}{ SIC } & \multicolumn{6}{|c|}{ ratio of semi-variances ${ }^{b}$} \\
\hline & & \multicolumn{3}{|c|}{ growth rates of trend deviations } & \multicolumn{3}{|c|}{ levels of trend deviations } \\
\hline & & real output & real output & nominal output & real output & real output & nominal output \\
\hline & & [OLS trend] & $\overline{[\mathrm{I}(1) \text { trend] }}$ & [I(1) trend] & [OLS trend] & $\overline{[\mathrm{I}(1) \text { trend] }}$ & [I(1) trend] \\
\hline manufacturing & $20-39$ & $.47 * *$ & $.50^{* *}$ & .67 & 1.45 & .77 & .91 \\
\hline food & 20 & $.54 * * *$ & $.55^{* * *}$ & 1.19 & 1.68 & .92 & 3.45 \\
\hline tobacco & 21 & 1.18 & .78 & 1.00 & $.70 *$ & .71 & 1.24 \\
\hline textiles & 22 & .82 & .95 & .76 & 1.49 & .50 & .61 \\
\hline apparel & 23 & .70 & .64 & .77 & .73 & $.21^{*}$ & .52 \\
\hline lumber & 24 & $.54 * *$ & .62 & $.44 *$ & $.45^{*}$ & $.21 * * *$ & $.41^{*}$ \\
\hline furniture & 25 & $.54 *$ & $.48^{*}$ & $.44 *$ & 1.32 & .69 & $.52 *$ \\
\hline paper & 26 & .70 & .64 & .85 & 1.49 & .41 & .77 \\
\hline $\begin{array}{l}\text { printing and } \\
\text { publishing }\end{array}$ & 27 & .76 & .72 & 1.06 & 1.02 & $.37^{*}$ & .66 \\
\hline chemicals & 28 & .63 & .55 & 1.48 & 1.48 & $.51 *$ & .75 \\
\hline $\begin{array}{l}\text { petroleum } \\
\text { refining }\end{array}$ & 29 & .66 & .70 & 1.44 & 1.70 & $.36^{*}$ & .55 \\
\hline $\begin{array}{l}\text { rubber and } \\
\text { plastics }\end{array}$ & 30 & .78 & .72 & .60 & 2.20 & $.53^{*}$ & .60 \\
\hline leather & 31 & 1.33 & 1.38 & .90 & .86 & $.31 * * *$ & 1.13 \\
\hline $\begin{array}{l}\text { stone, clay } \\
\text { and glass }\end{array}$ & 32 & .86 & .73 & .92 & 1.38 & .81 & .70 \\
\hline $\begin{array}{l}\text { primary } \\
\text { metals }\end{array}$ & 33 & $.48^{*}$ & $.67 *$ & $.60^{* *}$ & .93 & .41 & .48 \\
\hline $\begin{array}{l}\text { fabricated } \\
\text { metals }\end{array}$ & 34 & $.54 * *$ & $.50^{* *}$ & $.65^{* *}$ & 1.66 & .74 & .85 \\
\hline $\begin{array}{l}\text { nonelectrical } \\
\text { machinery }\end{array}$ & 35 & $.42 * *$ & $.59 * *$ & .70 & .68 & .77 & 1.16 \\
\hline $\begin{array}{l}\text { electrical } \\
\text { machinery }\end{array}$ & 36 & .70 & $.57^{* *}$ & .74 & 1.28 & .64 & .75 \\
\hline motor vehicles & 371 & 1.07 & 1.04 & 1.11 & $.60 *$ & $.36^{* *}$ & $.34 * * *$ \\
\hline $\begin{array}{l}\text { other } \\
\text { transportation }\end{array}$ & $37 x$ & .79 & .70 & .92 & 1.85 & 1.13 & 2.06 \\
\hline instruments & 38 & $.61^{*}$ & $.63^{*}$ & 1.66 & .80 & .76 & 2.44 \\
\hline miscellaneous & 39 & .89 & 1.10 & 1.21 & 1.06 & .67 & .72 \\
\hline
\end{tabular}

${ }^{a}$ The trend in industry log output is represented, alternatively, by the linear trend of log output [OLS trend] and by a cointegrating trend based on FRB utilization rates [I(1) trend]. Trend deviations in industry nominal output are the sum of log trend deviations in industry output and price, see text. Sample spans are 1967Q1-1991Q4 for SIC 21, 23, 24, 25, 27, 31, and 39, and 1954Q1-1991Q4 for remaining industries.

${ }^{b}$ Ratio of squared positive mean deviations over squared negative mean deviations. The relevant ratio is less than unity at $90 \%(*), 95 \%(* *)$, and $99 \%(* * *)$ confidence levels; standard errors are corrected for serial correlation using a Newey-West covariance construction with a bandwidth of \pm five quarters. 
Table II

Error Correction Decision Rules for Industry Producer Price Indexes ${ }^{a}$

$$
\Delta p_{t}=-A(1) \epsilon_{t-1}+A^{*}(L) \Delta p_{t-1}+S_{t}^{1}\left(G, \Delta p^{*}\right)+a_{t} .
$$

\begin{tabular}{|c|c|c|c|c|c|c|c|c|c|}
\hline \multirow[b]{2}{*}{ industry } & \multirow[b]{2}{*}{ SIC } & \multicolumn{3}{|c|}{$\begin{array}{c}\text { adjustment cost } \\
\text { parameters }\end{array}$} & \multirow[b]{2}{*}{$R^{2}$} & \multirow[b]{2}{*}{$S E E$} & \multirow[b]{2}{*}{$B G(12)^{b}$} & \multicolumn{2}{|c|}{$\begin{array}{c}\text { price trend }\left(\Delta p^{*}\right) \\
\text { expectations }\end{array}$} \\
\hline & & lag & $A(1)$ & $A^{*}(1)$ & & & & $L R\left(\Delta p^{* e}\right)^{c}$ & $\Delta R^{2 d}$ \\
\hline \multirow[t]{2}{*}{ manufacturing } & $20-39$ & 1 & $\begin{array}{r}.10 \\
(2.6)\end{array}$ & & .40 & .0106 & .00 & .00 & $.36(90 \%)$ \\
\hline & & 3 & $\begin{array}{r}.07 \\
(2.7)\end{array}$ & $\begin{array}{r}.63 \\
(13.2)\end{array}$ & .72 & .0068 & .31 & .96 & $.01(1 \%)$ \\
\hline food & 20 & 7 & $\begin{array}{r}.25 \\
(4.6)\end{array}$ & $\begin{array}{r}.58 \\
(3.8)\end{array}$ & .30 & .0311 & .61 & .13 & $.00(0 \%)$ \\
\hline tobacco & 21 & 2 & $\begin{array}{r}.18 \\
(3.5)\end{array}$ & $\begin{array}{l}-.12 \\
(1.7)\end{array}$ & .31 & .0193 & .35 & .96 & $.14(45 \%)$ \\
\hline textiles & 22 & 3 & $\begin{array}{r}.11 \\
(4.1)\end{array}$ & $\begin{array}{r}.50 \\
(8.4)\end{array}$ & .60 & .0108 & .25 & .27 & $.00(0 \%)$ \\
\hline apparel & 23 & 2 & $\begin{array}{r}.06 \\
(1.8)\end{array}$ & $\begin{array}{r}.60 \\
(8.6)\end{array}$ & .59 & .0049 & .45 & .12 & $.05(8 \%)$ \\
\hline lumber & 24 & 4 & $\begin{array}{r}.07 \\
(1.6)\end{array}$ & $\begin{array}{r}.48 \\
(3.5)\end{array}$ & .25 & .0288 & .87 & .27 & $.00(0 \%)$ \\
\hline furniture & 25 & 2 & $\begin{array}{r}.08 \\
(2.6)\end{array}$ & $\begin{array}{r}.21 \\
(3.8)\end{array}$ & .62 & .0058 & .47 & .59 & $.07(11 \%)$ \\
\hline paper & 26 & 2 & $\begin{array}{r}.13 \\
(4.6)\end{array}$ & $\begin{array}{r}.60 \\
(11.2)\end{array}$ & .62 & .0104 & .39 & .20 & $.03(5 \%)$ \\
\hline $\begin{array}{l}\text { printing and } \\
\text { publishing }\end{array}$ & 27 & 2 & $\begin{array}{r}.11 \\
(5.1)\end{array}$ & $\begin{array}{r}.50 \\
(9.4)\end{array}$ & .65 & .0109 & .69 & .51 & $.03(5 \%)$ \\
\hline chemicals & 28 & 3 & $\begin{array}{r}.06 \\
(3.2)\end{array}$ & $\begin{array}{r}.73 \\
(15.8)\end{array}$ & .75 & .0107 & .62 & .28 & $.01(1 \%)$ \\
\hline $\begin{array}{l}\text { petroleum } \\
\text { refining }\end{array}$ & 29 & 7 & $\begin{array}{r}.30 \\
(5.5)\end{array}$ & $\begin{array}{r}.80 \\
(5.8)\end{array}$ & .43 & .0552 & .11 & .24 & $.05(12 \%)$ \\
\hline $\begin{array}{l}\text { rubber and } \\
\text { plastics }\end{array}$ & 30 & 2 & $\begin{array}{r}.19 \\
(4.9)\end{array}$ & $\begin{array}{r}.51 \\
(9.9)\end{array}$ & .65 & .0090 & .56 & .20 & $.08(12 \%)$ \\
\hline
\end{tabular}

(Footnotes at end of table) 
Table II Cont.

Error Correction Decision Rules for Industry Producer Price Indexes ${ }^{a}$

$\Delta p_{t}=-A(1) \epsilon_{t-1}+A^{*}(L) \Delta p_{t-1}+S_{t}^{1}\left(G, \Delta p^{*}\right)+a_{t}$.

\begin{tabular}{|c|c|c|c|c|c|c|c|c|c|}
\hline \multirow[b]{2}{*}{ industry } & \multirow[b]{2}{*}{ SIC } & \multicolumn{3}{|c|}{$\begin{array}{c}\text { adjustment cost } \\
\text { parameters }\end{array}$} & \multirow[b]{2}{*}{$R^{2}$} & \multirow[b]{2}{*}{$S E E$} & \multirow[b]{2}{*}{$B G(12)^{b}$} & \multicolumn{2}{|c|}{$\begin{array}{c}\text { price trend }\left(\Delta p^{*}\right) \\
\text { expectations }\end{array}$} \\
\hline & & lag & $A(1)$ & $A^{*}(1)$ & & & & $L R\left(\Delta p^{* e}\right)^{c}$ & $\Delta R^{2 d}$ \\
\hline leather & 31 & 5 & $\begin{array}{r}.08 \\
(1.7)\end{array}$ & $\begin{array}{r}.29 \\
(1.6)\end{array}$ & .38 & .0445 & .76 & .26 & $.00(0 \%)$ \\
\hline $\begin{array}{l}\text { stone, clay } \\
\text { and glass }\end{array}$ & 32 & 5 & $\begin{array}{r}.07 \\
(3.4)\end{array}$ & $\begin{array}{r}.62 \\
(9.7)\end{array}$ & .67 & .0081 & .31 & .70 & $.03(4 \%)$ \\
\hline $\begin{array}{l}\text { primary } \\
\text { metals }\end{array}$ & 33 & 2 & $\begin{array}{r}.11 \\
(2.7)\end{array}$ & $\begin{array}{r}.56 \\
(6.3)\end{array}$ & .41 & .0201 & .94 & .60 & $.05(12 \%)$ \\
\hline $\begin{array}{l}\text { fabricated } \\
\text { metals }\end{array}$ & 34 & 2 & $\begin{array}{r}.10 \\
(4.7)\end{array}$ & $\begin{array}{r}.71 \\
(13.9)\end{array}$ & .68 & .0099 & .63 & .14 & $.05(7 \%)$ \\
\hline $\begin{array}{l}\text { nonelectrical } \\
\text { machinery }\end{array}$ & 35 & 5 & $\begin{array}{r}.08 \\
(3.1)\end{array}$ & $\begin{array}{r}.61 \\
(12.4)\end{array}$ & .83 & .0046 & .64 & .20 & $.03(4 \%)$ \\
\hline $\begin{array}{l}\text { electrical } \\
\text { machinery }\end{array}$ & 36 & 4 & $\begin{array}{r}.08 \\
(5.8)\end{array}$ & $\begin{array}{r}.27 \\
(3.6)\end{array}$ & .75 & .0052 & .51 & .18 & $.02(3 \%)$ \\
\hline $\begin{array}{l}\text { motor } \\
\text { vehicles }\end{array}$ & 371 & 5 & $\begin{array}{r}.15 \\
(4.9)\end{array}$ & $\begin{array}{r}.13 \\
(1.2)\end{array}$ & .73 & .0089 & .90 & .37 & $.00(0 \%)$ \\
\hline $\begin{array}{l}\text { other } \\
\text { transportation }\end{array}$ & $37 x$ & 5 & $\begin{array}{r}.08 \\
(3.9)\end{array}$ & $\begin{array}{r}.42 \\
(4.9)\end{array}$ & .67 & .0076 & .60 & .24 & $.06(9 \%)$ \\
\hline instruments & 38 & 2 & $\begin{array}{r}.12 \\
(4.0)\end{array}$ & $\begin{array}{r}.22 \\
(2.9)\end{array}$ & .26 & .0181 & .98 & .56 & $.03(12 \%)$ \\
\hline miscellaneous & 39 & 2 & $\begin{array}{r}.15 \\
(3.6)\end{array}$ & $\begin{array}{r}.26 \\
(3.7)\end{array}$ & .39 & .0138 & .18 & .96 & $.07(18 \%)$ \\
\hline
\end{tabular}

${ }^{a}$ Sample span 1954Q1 - 1991Q4; t-ratios in parentheses. As in the text, $p$ denotes the log producer price; $p^{*}$ is the cointegrated price trend; $\epsilon_{t}$ is the cointegrating discrepancy, $p_{t}-p_{t}^{*}$; and $S_{t}^{1}\left(G, \Delta p^{*}\right)$ is the present-value effect of anticipated price trend changes.

${ }^{b}$ Breusch-Godfrey test (p-value) of residual autocorrelation (12 lags).

${ }^{c}$ Likelihood ratio test (p-value) of RE restrictions on predictions of price trend changes, $\Delta p^{* e}$.

${ }^{d}$ Change in $R^{2}$ due to present-value effect of anticipated price trend changes, $S_{t}^{1}\left(G, \Delta p^{*}\right)$. 
Table III

Adjustments of Industry Prices to Ouput $(u)$ Gaps and Price $(\epsilon)$ Gaps $^{a}$

$\Delta p_{t}=-A(1) \epsilon_{t-1}+A^{*}(L) \Delta p_{t-1}+S_{t}^{1}\left(G, \Delta p^{*}\right)+D(L)\left[h_{u}^{\prime} z_{t-1}\right]-\left[A^{+}(1)-A(1)\right] \epsilon_{t-1}^{+}+a_{t}$.

\begin{tabular}{|c|c|c|c|c|c|c|c|c|c|c|c|}
\hline \multirow[b]{2}{*}{ SIC } & \multicolumn{2}{|c|}{$\begin{array}{l}\text { adjustment } \\
\text { costs }\end{array}$} & \multirow[b]{2}{*}{$R^{2}$} & \multicolumn{2}{|c|}{$\begin{array}{c}\text { output }^{b} \\
\text { gap effects }\end{array}$} & \multicolumn{3}{|c|}{$\begin{array}{c}\text { asymmetric price }^{c} \\
\text { gap effects }\end{array}$} & \multicolumn{3}{|c|}{$\begin{array}{c}\text { mean }^{d} \\
\text { lags }\end{array}$} \\
\hline & $A(1)$ & $A^{*}(1)$ & & $\mathrm{LR}(\mathrm{u})$ & $\mathrm{D}(1)$ & $L R\left(\epsilon^{+}, \epsilon^{-}\right)$ & $L R\left(0, \epsilon^{-}\right)$ & $A^{+}(1)$ & $M L^{-}$ & & $M L^{+}$ \\
\hline 20-39 & $\begin{array}{r}.13 \\
(2.9)\end{array}$ & $\begin{array}{r}.63 \\
(12.8)\end{array}$ & .75 & .03 & $\begin{array}{r}.19 \\
(1.5)\end{array}$ & .04 & .91 & $\begin{array}{r}.00 \\
(0.0)\end{array}$ & 1.8 & & 6.2 \\
\hline 20 & $\begin{array}{r}.24 \\
(4.4)\end{array}$ & $\begin{array}{r}.52 \\
(3.4)\end{array}$ & .33 & .07 & $\begin{array}{l}1.61 \\
(2.3)\end{array}$ & .14 & .00 & & & 1.0 & \\
\hline 21 & $\begin{array}{r}.27 \\
(3.0)\end{array}$ & $\begin{array}{l}-.20 \\
(2.5)\end{array}$ & .33 & .90 & & .48 & .62 & $\begin{array}{r}.04 \\
(0.4)\end{array}$ & 3.4 & & 29.8 \\
\hline 22 & $\begin{array}{r}.19 \\
(3.5)\end{array}$ & $\begin{array}{r}.44 \\
(7.1)\end{array}$ & .64 & .00 & $\begin{array}{r}.42 \\
(2.3)\end{array}$ & .31 & .21 & $\begin{array}{r}.07 \\
(1.2)\end{array}$ & 2.1 & & 6.7 \\
\hline 23 & $\begin{array}{r}.18 \\
(2.8)\end{array}$ & $\begin{array}{r}.45 \\
(6.5)\end{array}$ & .62 & .17 & & .03 & .19 & $\begin{array}{r}-.06 \\
(-1.1)\end{array}$ & 1.9 & & 12.8 \\
\hline 24 & $\begin{array}{r}.07 \\
(1.6)\end{array}$ & $\begin{array}{r}.48 \\
(3.5)\end{array}$ & .25 & .44 & & 1.00 & .27 & & & 6.7 & \\
\hline 25 & $\begin{array}{c}.12 \\
(1.8)\end{array}$ & $\begin{array}{r}.16 \\
(2.7)\end{array}$ & .61 & .48 & & .21 & .84 & $\begin{array}{r}.02 \\
(0.3)\end{array}$ & 6.0 & & 41.0 \\
\hline 26 & $\begin{array}{r}.17 \\
(3.7)\end{array}$ & $\begin{array}{r}.56 \\
(10.5)\end{array}$ & .66 & .00 & $\begin{array}{r}.96 \\
(3.5)\end{array}$ & .08 & .89 & $\begin{array}{r}.00 \\
(0.1)\end{array}$ & 1.6 & & 6.3 \\
\hline 27 & $\begin{array}{r}.16 \\
(4.4)\end{array}$ & $\begin{array}{r}.45 \\
(8.4)\end{array}$ & .66 & .21 & & .07 & .32 & $\begin{array}{r}.05 \\
(1.4)\end{array}$ & 2.4 & & 9.9 \\
\hline 28 & $\begin{array}{r}.09 \\
(3.0)\end{array}$ & $\begin{array}{r}.69 \\
(12.2)\end{array}$ & .78 & .02 & $\begin{array}{l}1.33 \\
(2.3)\end{array}$ & .02 & .77 & $\begin{array}{c}.02 \\
(0.6)\end{array}$ & 2.4 & & 14.5 \\
\hline 29 & $\begin{array}{r}.30 \\
(5.5)\end{array}$ & $\begin{array}{r}.80 \\
(5.8)\end{array}$ & .43 & .79 & & .52 & .00 & & & -0.3 & \\
\hline 30 & $\begin{array}{r}.19 \\
(4.9)\end{array}$ & $\begin{array}{r}.51 \\
(9.9)\end{array}$ & .65 & .27 & & .24 & .10 & & & 1.6 & \\
\hline 31 & $\begin{array}{c}.08 \\
(1.8)\end{array}$ & $\begin{array}{r}.30 \\
(1.7)\end{array}$ & .41 & .07 & $\begin{array}{l}3.57 \\
(1.0)\end{array}$ & .15 & .03 & & & 7.6 & \\
\hline
\end{tabular}

(Footnotes at end of table.) 
Table III Cont.

Adjustments of Industry Prices to Ouput ( $u$ ) Gaps and Price $(\epsilon)$ Gaps $^{a}$

$$
\Delta p_{t}=-A(1) \epsilon_{t-1}+A^{*}(L) \Delta p_{t-1}+S_{t}^{1}\left(G, \Delta p^{*}\right)+D(L)\left[h_{u}^{\prime} z_{t-1}\right]-\left[A^{+}(1)-A(1)\right] \epsilon_{t-1}^{+}+a_{t} .
$$

\begin{tabular}{|c|c|c|c|c|c|c|c|c|c|c|c|}
\hline \multirow[b]{2}{*}{ SIC } & \multicolumn{2}{|c|}{$\begin{array}{l}\text { adjustment } \\
\text { costs }\end{array}$} & \multirow[b]{2}{*}{$R^{2}$} & \multicolumn{2}{|c|}{$\begin{array}{c}\text { output }^{b} \\
\text { gap effects }\end{array}$} & \multicolumn{3}{|c|}{$\begin{array}{c}\text { asymmetric price } \\
\text { gap effects }\end{array}$} & \multicolumn{3}{|c|}{$\begin{array}{c}\text { mean }^{d} \\
\text { lags }\end{array}$} \\
\hline & $A(1)$ & $A^{*}(1)$ & & $\operatorname{LR}(u)$ & $\mathrm{D}(1)$ & $L R\left(\epsilon^{+}, \epsilon^{-}\right)$ & $L R\left(0, \epsilon^{-}\right)$ & $A^{+}(1)$ & $M L^{-}$ & & $M L^{+}$ \\
\hline 32 & $\begin{array}{r}.11 \\
(3.8)\end{array}$ & $\begin{array}{r}.62 \\
(10.2)\end{array}$ & .72 & .00 & $\begin{array}{r}.70 \\
(3.0)\end{array}$ & .07 & .35 & $\begin{array}{c}.04 \\
(1.0)\end{array}$ & 2.4 & & 9.3 \\
\hline 33 & $\begin{array}{c}.18 \\
(1.8)\end{array}$ & $\begin{array}{r}.48 \\
(5.1)\end{array}$ & .44 & .08 & $\begin{array}{r}.30 \\
(1.7)\end{array}$ & .42 & .32 & $\begin{array}{r}.09 \\
(1.0)\end{array}$ & 1.9 & & 4.9 \\
\hline 34 & $\begin{array}{r}.23 \\
(4.6)\end{array}$ & $\begin{array}{r}.53 \\
(8.9)\end{array}$ & .67 & .40 & & .00 & .86 & $\begin{array}{r}.00 \\
(0.0)\end{array}$ & 1.0 & & 9.6 \\
\hline 35 & $\begin{array}{r}.15 \\
(3.5)\end{array}$ & $\begin{array}{r}.57 \\
(12.3)\end{array}$ & .85 & .61 & & .00 & .07 & $\begin{array}{r}-.06 \\
(-1.6)\end{array}$ & 1.9 & & 11.9 \\
\hline 36 & $\begin{array}{c}.08 \\
(5.8)\end{array}$ & $\begin{array}{r}.27 \\
(3.6)\end{array}$ & .75 & .86 & & .30 & .06 & & & 7.7 & \\
\hline 371 & $\begin{array}{r}.16 \\
(5.3)\end{array}$ & $\begin{array}{r}.01 \\
(0.1)\end{array}$ & .75 & .02 & $\begin{array}{l}-.17 \\
(-2.1)\end{array}$ & .74 & .03 & & & 5.0 & \\
\hline $37 x$ & $\begin{array}{r}.19 \\
(3.9)\end{array}$ & $\begin{array}{r}.25 \\
(2.8)\end{array}$ & .69 & .82 & & .00 & .51 & $\begin{array}{r}-.00 \\
(-0.2)\end{array}$ & 3.0 & & 29.1 \\
\hline 38 & $\begin{array}{r}.26 \\
(4.0)\end{array}$ & $\begin{array}{r}.14 \\
(1.9)\end{array}$ & .29 & .96 & & .01 & .91 & $\begin{array}{l}-.01 \\
(-0.2)\end{array}$ & 2.3 & & 15.5 \\
\hline 39 & $\begin{array}{r}.15 \\
(3.6)\end{array}$ & $\begin{array}{r}.26 \\
(3.7)\end{array}$ & .39 & .47 & & .27 & .01 & & & 3.9 & \\
\hline
\end{tabular}

${ }^{a}$ Sample span 1954Q1 - 1991Q4; t-ratios in parentheses. As in the text, $p$ denotes the log producer price; $p^{*}$ is the cointegrated price trend; $\epsilon_{t}$ is the price gap, $p_{t}-p_{t}^{*} ; \epsilon_{t}^{+}$and $\epsilon_{t}^{-}$denote the positive and negative price gaps. $S_{t}^{1}\left(G, \Delta p^{*}\right)$ is the present-value effect of anticipated price trend changes; and $D(L)\left[h_{u}^{\prime} z_{t-1}\right]$ is the present-value effect of anticipated output gaps.

${ }^{b} L R(u)$ is the p-value to accept industry output gap terms, $D(L)\left[h_{u}^{\prime} z_{t-1}\right]$, as significant regressors.

${ }^{c} L R\left(\epsilon^{+}, \epsilon^{-}\right)$is the p-value to accept different error-correction responses to the split price gaps, $\epsilon^{+}$and $\epsilon^{-} ; L R\left(0, \epsilon^{-}\right)$ is the $\mathrm{p}$-value to reject a zero error-correction response to positive price gaps, $\epsilon^{+}$.

${ }^{d}$ Mean lag in quarters, conditional on the sign of the price gap. For several industries, the mean lag estimate for positive price gaps, $M L^{+}$, is constructed by adding one or two standard errors to nonpositive estimates of $A^{+}(1)$. 
Table IV

Proximate Causes of Asymmetric Pricing

\begin{tabular}{|c|c|c|c|c|}
\hline \multirow[b]{3}{*}{ industry mean contrasts ${ }^{b}$} & \multicolumn{4}{|c|}{ industry characteristics ${ }^{a}$} \\
\hline & $\begin{array}{l}\text { herfindahl } \\
\text { index (HF) }\end{array}$ & $\begin{array}{l}\text { labor } \\
\text { share (LS) }\end{array}$ & $\begin{array}{l}\text { liquid asset } \\
\text { ratio (LA) }\end{array}$ & $\begin{array}{l}\text { trend inflation } \\
\text { variation }(\mathrm{TI})\end{array}$ \\
\hline & & & & \\
\hline $\begin{array}{l}\text { mean of symmetric } \\
\text { pricing industries }\end{array}$ & 754 & .24 & .21 & .59 \\
\hline $\begin{array}{l}\text { mean of asymmetric } \\
\text { pricing industries }\end{array}$ & 758 & .30 & .29 & .88 \\
\hline $\begin{array}{l}\mathrm{p} \text {-values for } \\
\text { mean difference: }\end{array}$ & & & & \\
\hline - equal variances & .50 & .08 & .08 & .02 \\
\hline - unequal variances & .50 & .21 & .18 & .04 \\
\hline $\begin{array}{l}\text { regressions to explain } \\
\text { asymmetric pricing index }\end{array}$ & & & & \\
\hline bivariate correlations: & & & & \\
\hline $\begin{array}{l}\text { with industry } \\
\text { characteristic }\end{array}$ & $\begin{array}{r}.45 \\
(1.7)\end{array}$ & $\begin{array}{r}.14 \\
(0.5)\end{array}$ & $\begin{array}{r}.60 \\
(2.5)\end{array}$ & $\begin{array}{r}.53 \\
(2.1)\end{array}$ \\
\hline $\begin{array}{l}\text { with rank of industry } \\
\text { characteristic }\end{array}$ & $\begin{array}{r}.23 \\
(0.8)\end{array}$ & $\begin{array}{r}.22 \\
(0.7)\end{array}$ & $\begin{array}{r}.54 \\
(2.1)\end{array}$ & $\begin{array}{r}.53 \\
(2.1)\end{array}$ \\
\hline multivariate regressions: & & & & \\
\hline$\left(R^{2}=.53\right)$ & $\begin{array}{l}.85 \times 10^{-3} \\
(0.8)\end{array}$ & $\begin{array}{l}-.15 \\
(-0.0)\end{array}$ & $\begin{array}{c}9.4 \\
(1.4)\end{array}$ & $\begin{array}{c}2.7 \\
(1.3)\end{array}$ \\
\hline$\left(R^{2}=.48\right)$ & & & $\begin{array}{l}11.2 \\
(1.9)\end{array}$ & $\begin{array}{c}2.9 \\
(1.5)\end{array}$ \\
\hline
\end{tabular}

${ }^{a} \mathrm{HF}$ - Herfindahl concentration index; LS - employee compensation share of gross output; LA - ratio of net liquid assets to equity; TI - ratio of mean to standard deviation of four-quarter inflation in industry price trend.

${ }^{b}$ Industries exhibiting symmetric or asymmetric pricing as indicated in table III. The p-values are for a one-tail test that the mean of asymmetric industries exceeds the mean of symmetric industries; $p$-values for unequal variances are based on Cochran's test, Lauer and Han [1974].

${ }^{c}$ Dependent variable, defined only for industries exhibiting asymmetric pricing responses, is the ratio of mean lags shown in table III for positive and negative price gaps, $M L^{+} / M L^{-}$. Parentheses contain t-ratios. 